\title{
71/2 Jahre bis zur Ausheilung einer Unterschenkelfraktur
}

\author{
Klaus Wenda, Bertram Regenbrecht
}

Verlauf

1/2000 Tibiafraktur am Übergang vom mittleren zum distalen Drittel, auf den postoperativen Bildern

Abb. 1

fällt Sprengung der Tibia im mittleren Drittel auf

7/2000 Die Fraktur hat sich etwas verkürzt, zunehmende Varusfehlstellung

Abb. 2

9/2000 Es wird erstmals deutlich, dass der Nagel im mittleren Drittel dorsal „im Freien“ steht

Abb. 3

3/2004 Rettungsversuch mit einer winkelstabilen Platte und Spongiosaplastik

Abb. 4

$6 / 2004$

Bruch der winkelstabilen Schrauben

Abb. 4

$7 / 2005$

Entfernung des Nagels, Achsenkorrektur und winkelstabile Platte

Abb. 5

9/2005

Plattenbruch, eneute Plattenosteosynthese

Abb. 6

$1 / 2006$

erneuter Plattenbruch, Resektion der Pseudarthrose und Callusdistraktion

Abb. 7

9/2007

Ausheilung nach 71/2 Jahren

Abb. 8
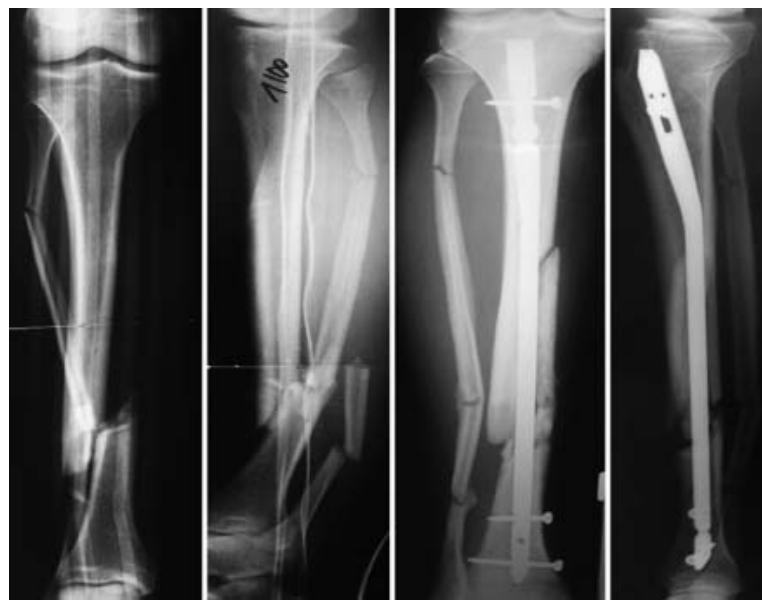

Abb. 1 1/2000: Unterschenkelfraktur mit Tibiafraktur am Übergang vom mittleren zum distalen Drittel, auf dem postoperativen Bild erkennt man, dass es zu einer Sprengung des mittleren Drittels gekommen ist.

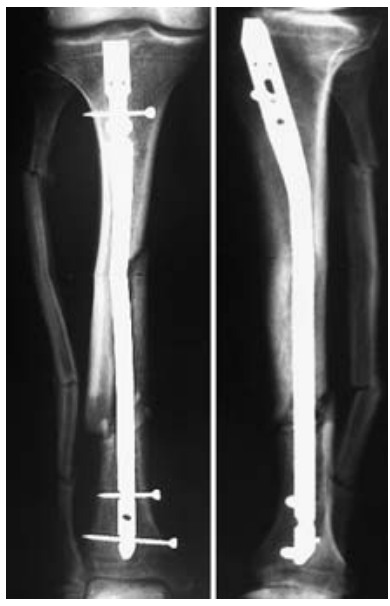

Abb. 2 7/2000: Die Tibiafraktur hat sich etwas verkürzt, soweit wie es der proximale Verriegelungsbolzen im ovalen Loch erlaubt, eine gewisse Varusfehlstellung ist eingetreten.

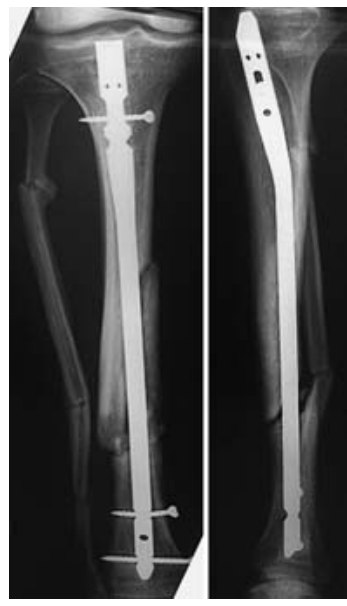

Abb. 3 9/2000: Durch etwas andere Projektion ist erstmals klar, dass der Nagel im mittleren Drittel dorsal „im Freien steht", wegen mäßiger Beschwerden wird abgewartet. 


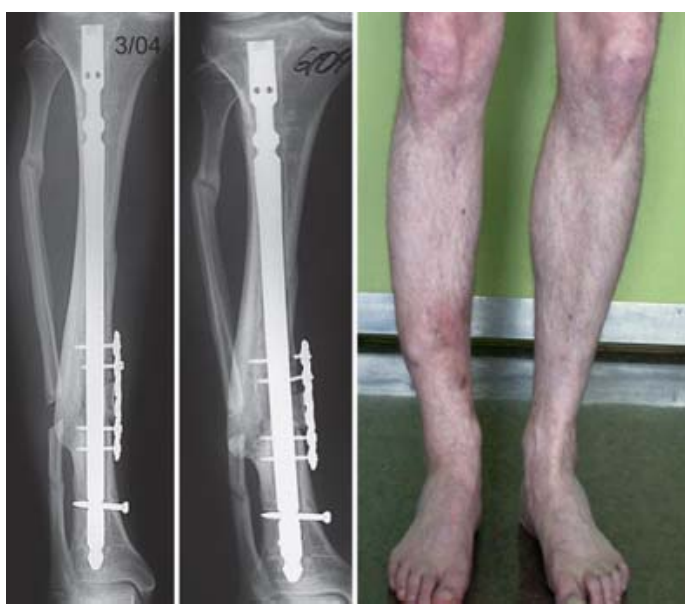

Abb. 4 3/2004: Rettungsversuch mit einer winkelstabilen Platte und Spongiosaplastik. 6/2004: Schraubenbruch und zunehmende Varusfehlstellung.

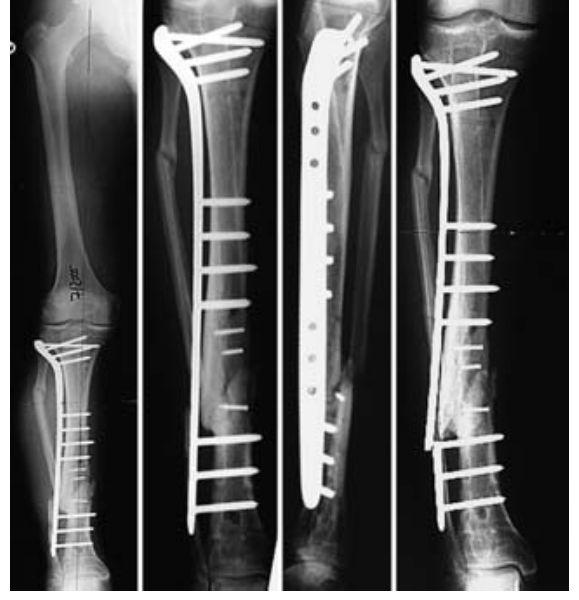

Abb. 5 7/2005: Achsenkorrektur im Bereich der Pseudarthrose und Stabilisierung mit winkelstabiler Platte. 9/2005: Plattenbruch.

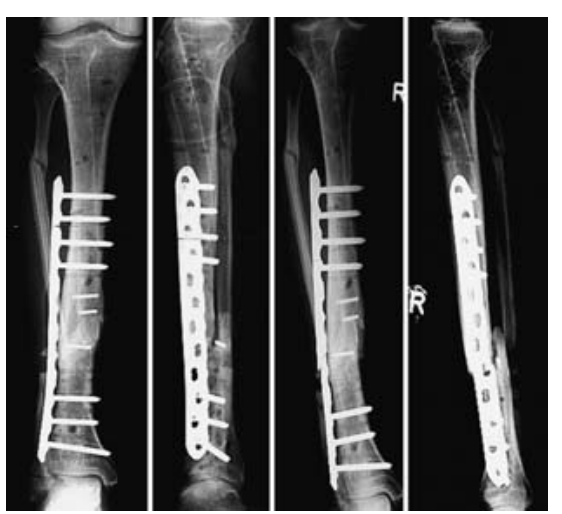

Abb. 6 9/2005: Erneute Plattenosteosynthese. 1/2006: Erneuter Plattenbruch.

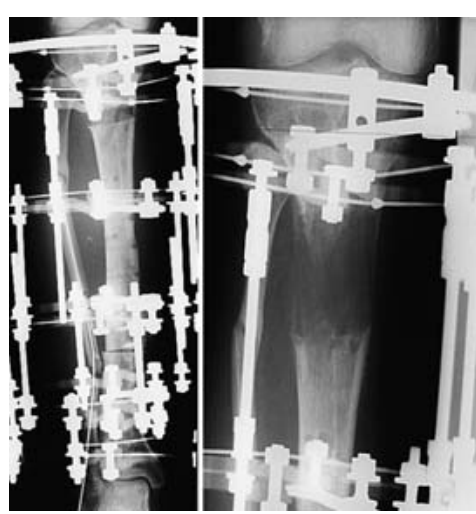

Abb. 7 1/2006: Resektion der Pseudarthrose und Callusdistraktion.

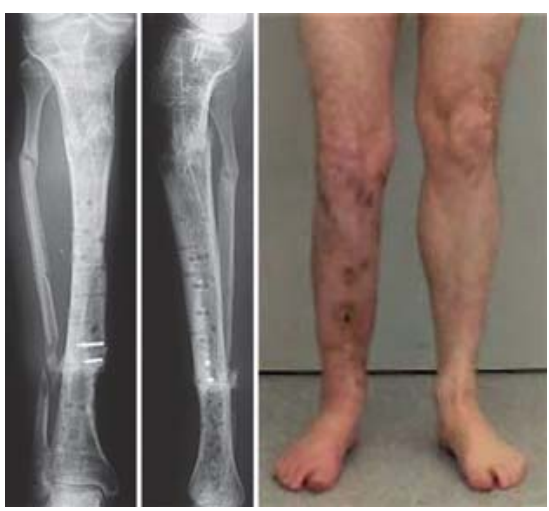

Abb. 8 9/2007: Ausheilung 71/2 Jahre nach Unterschenkelfraktur.

Prof. Dr. med. Klaus Wenda

Klinikdirektor

\section{Dr. med. Bertram Regenbrecht}

Chefarzt Roland-Klinik Bremen, ehemals Dr. Horst-Schmidt-Kliniken Wiesbaden

Resektion der Pseudarthrose und Callusdistraktion erzielt werden.

Die Lehre aus diesem Fall: Die Achsenverhältnisse hätten frühzeitiger korrigiert werden müssen, die Resektion der Pseudarthrose und anschließende Callusdistraktion ist eine Option in verzweifelten Fällen. 